\title{
Editorial
}

\section{Arne Floh}

Dear Madam or Sir,

The last issue of 2012 comprises two empirical and two theoretical/conceptual manuscripts:

The issue begins with a piece of research by Torsten Gerpott (University of Duisburg-Essen) and Mathias Paukert (University of Duisburg-Essen). The authors develop hypotheses on direct and indirect associations between eight features of customer interactions with call center response systems and the care satisfaction of calling customers. The hypotheses are tested in a sample of 108 customers of mobile communication network operators in Germany. The analysis shows that the care satisfaction of calling customers is most closely related to the quality of the service process. Following that, the authors provide implications for the management of call centers.

The second article, written by Robert Sobotka (Telemark Marketing) and Ewald Judt (WU Wien), covers the interesting topic of regional market orientation. Whereas most prior research has focused on the food industry, the authors apply the concept to the financial industry. Using a large empirical study, the authors show a significant link be- tween regional market orientation and word-of-mouth. The article ends with an outlook and suggestions for further research.

Based on a comprehensive literature review, the third article, by Ulya Haenraets, Julia Ingwald, and Vanessa Hasselhoff (TU Dortmund), systemizes existing studies with three aims: disambiguation, demonstrating classification options for seals and identifying factors that influence the effects of the use of quality seals, as well as naming these effects. The authors conclude that the use of quality seals generally has a positive effect. Additionally, the results mainly demonstrate that there are incorrect perceptions of the certification process and criteria.

Finally, the fourth article of this issue, by Nejc M. Jakopin (University of Duisburg-Essen), presents a new perspective on the music industry aimed at identifying new revenue sources. The musicians' needs pyramid takes center stage and serves as a tool to link the activities and goals of artists, musicians, and performers in the music industry. A survey of 247 artists shows that they perceive performing, creating, and recording to be the key activities.

Arne Floh $(\bowtie)$

WU (Wirtschaftsuniversität Wien)

Augasse 2-6, 1090 Wien

e-mail: arne.floh@wu.ac.at 